\title{
Effect of geometry on crashworthiness parameters of natural kenaf fibre reinforced composite hexagonal tubes
}

\begin{abstract}
The effect of geometry on energy absorption capability and load-carrying capacity of natural kenaf fibre reinforced composite hexagonal tubes had been investigated experimentally. A series of experiments were carried out for composite hexagonal tubes with different angles from a range of $40-60^{\circ}$ in $5^{\circ}$ steps. This range is suitable for obtaining a regular hexagonal shape. Kenaf fibre mat form was used in this work due to several advantages such as low cost, no health risk, light weight and availability. The kenaf density was usage $0.17 \mathrm{~g} / \mathrm{cm} 3$ with thickness of $4 \mathrm{~mm}$. Results demonstrated that structures failed in few distinct failure modes. Precisely in progressive failure mode and fragmentation failure associated with longitudinal cracks. The composite tube with $\beta=60^{\circ}$ exhibited local buckling failure mode and displayed the highest specific energy absorption capability equal to $9.2 \mathrm{~J} / \mathrm{g}$. On the other hand, new crashworthiness parameter has been introduced as catastrophic failure mode indicator (CFMI). Furthermore, typical load-deformation histories were presented and discussed.
\end{abstract}

Keyword: Geometry; Energy absorption capability; Load-carrying capacity; Natural kenaf fibre; Hexagonal tubes 